\title{
Genetic stabilization by p53 involves growth regulatory and repair pathways
}

\author{
Lisa Wiesmüller ${ }^{\dagger}$ \\ Heinrich-Pette-Institut für Experimentelle Virologie und Immunologie an der Universität \\ Hamburg, Martinistr. 52, 20251 Hamburg, Germany
}

\begin{abstract}
p53 performs a plethora of activities, which are directed towards the maintenance of the genomic integrity and constitute its universal role as a tumor suppressor. 1000 to 10000 latent p53 molecules are permanently available in order to monitor DNA exchange processes in mitotically growing cells. After the introduction of major DNA injuries the levels of posttranslationally modified p53 proteins rise, which in turn transcriptionally signal transient cell cycle arrest or apoptotic cell death, depending on the extent of damage. Taken together, p53 inhibits the manifestation of genomic instabilities at different control levels both during naturally occurring metabolic processes and in response to genotoxic treatments.
\end{abstract}

\section{GENOMIC STABILIZATION VIA CHECKPOINT CONTROL}

Loss of p53 function by either mutation, nuclear exclusion, complex inactivation, or accelerated degradation via the newly discovered ARF-MDM2 pathway are observed in the majority of human tumors $[1,2]$. The results of extensive research efforts have indicated that cell cycle control and the initiation of apoptotic cell death by p53 represent important pathways to suppress genomic instabilities, thereby preventing tumorigenesis $[3,4]$. p53-dependent checkpoint functions are triggered by DNA strand breaks introduced either directly, e.g., via ionizing irradiation, or indirectly, after the conversion of DNA adducts by DNA repair or replication [5]. An alternative signal transduction mechanism involving p53 seems to emanate from stalled RNA polymerases, e.g., after UV irradiation [6]. DNA damage activates p53 through posttranslational modifications by specific kinases, such as the strand break sensor Atm, acetylases, and poly(ADP-ribose)polymerase, which prevent proteolysis and enhance binding of p53 to consensus sequences within the genome [7-9]. Among the products of p53 target genes, the cyclin-dependent kinase inhibitor $\mathrm{p} 21^{\mathrm{WAF} 1 / \mathrm{CIP} 1}$ is essential for the execution of cell cycle arrest at the G1/S transition and to sustain a G2 arrest under certain circumstances $[4,10]$. The product of a 14-3-3 gene, which is also transcriptionally activated by $\mathrm{p} 53$, was reported to inactivate the protein phosphatase Cdc25C by sequestration [11]. Cdc25C is required for the activation of Cdc2 kinase at the G2/M checkpoint. Contrary opinions exist on a possible role of the p53responsive gene GADD45 in excision repair [12-14]. Meanwhile, functions of GADD45 in chromatin remodeling and of GADD45-p21 complexes in cell cycle regulation were proposed $[15,16]$. Apoptotic signaling involves transcriptionindependent pathways [17] and the activation of target genes, such as bax and IGF-BP3, encoding antagonists of Bcl-2 and insulin-like growth factor-1, respectively [4].

From these observations, it has been concluded that genomic stabilization and tumor suppression by $\mathrm{p} 53$ rely on cell cycle arrest at the G1/S transition, which prevents the manifestation of unrepaired chromosome alterations, on cell cycle arrest at the G2/M transition, which inhibits the distribution of defective genomes, and on the initiation of apoptosis after the introduction of irrepairable damage. This view is in agreement with the phenotype of p53/mice, which accumulate chromosomal aberrations and suffer from fatal tumors within 6 months [18]. However, p21/mice do not show increased cancer susceptibilities [19], raising the possibility that activities of $\mathrm{p} 53$, other than those related to growth control, might contribute to the suppression of tumor formation. Even further, according to a recent report, p53 seems to retain tumor suppressor functions in mice after treatment with PFT $\alpha$, a drug, which had been selected due to its properties to specifically inactivate p53-dependent transcription and apoptosis [20].

\section{INVOLVEMENT IN DNA REPAIR}

Ideas on an active participation of $\mathrm{p} 53$ in processes of the DNA metabolism were inspired by the discoveries of enzymatic activities, such as the reannealing of short DNA stretches $[21,22]$ and the $3^{\prime}$ to $5^{\prime}$ exonuclease activity [23]. p53 also binds to the two helicase components, XPB and XPD, of the dual transcription initiation/repair factor TFIIH, to CSB, another helicase involved in nucleotide excision repair, and to the Werner's Syndrome Protein, a helicase and exonuclease with putative functions in DNA replication $[4,24,25]$. Several groups reported on defective nucleotide excision repair in cells lacking wild-type p53, as determined by the removal of pyrimidine dimers $[26,27]$. Others noticed an in- 


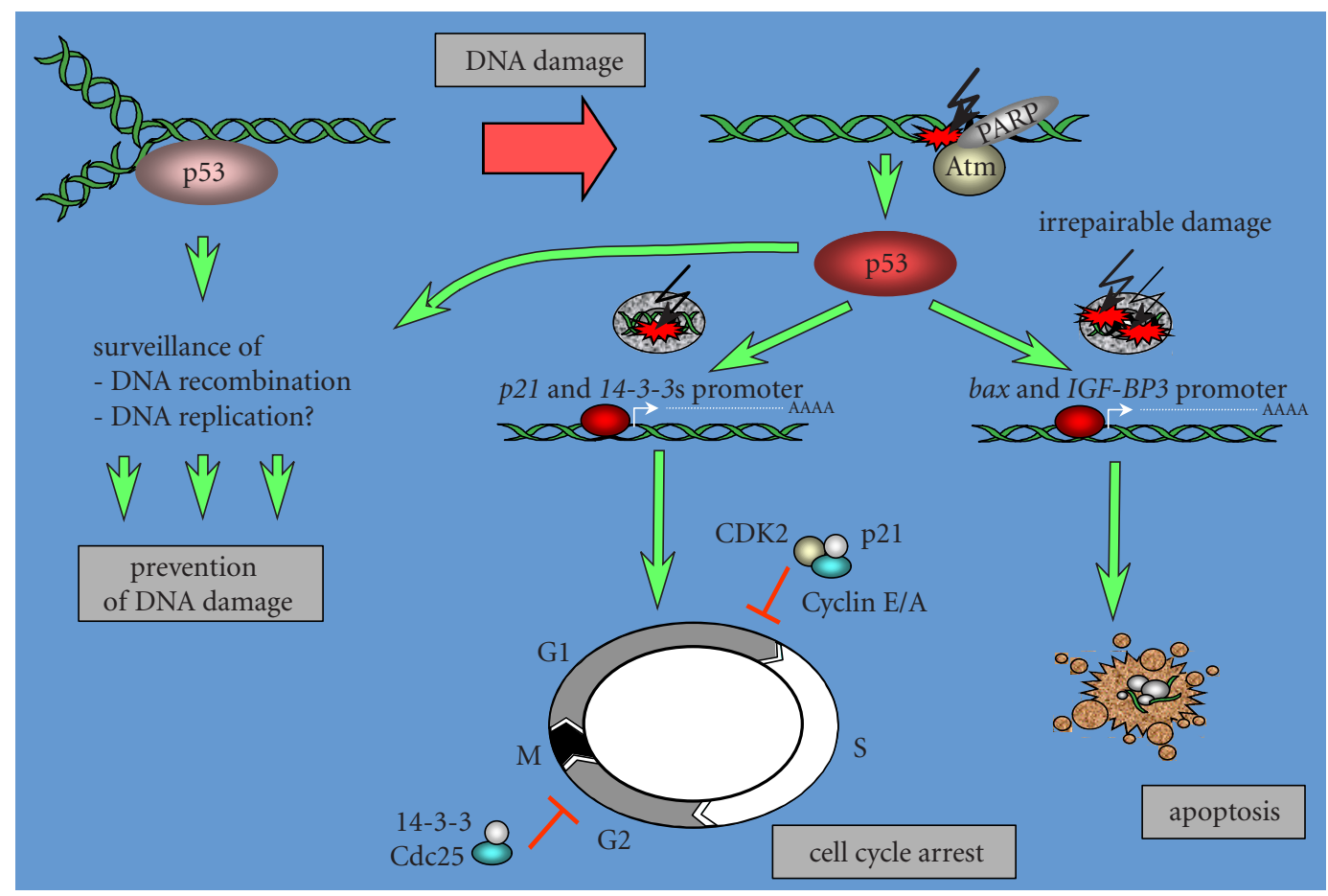

FIGURE 1: Maintenance of the genomic stability by multiple functions of p53. p53 surveils the genomic integrity via a hierarchy of different functions both during proliferation-associated processes and during cellular stress situations.

crease in sister chromatid exchanges after UV in cells from p53/mice rather than differences in excision repair [28]. The latter observation might point towards a role of p53 in UVirradiation induced DNA exchange events, since recombination is frequently coupled to DNA synthesis in order to allow the removal of unrepaired lesions, such as unexcised photoproducts.

Indeed, using different test systems, several groups found that p53 suppresses spontaneous inter- and intrachromosomal homologous recombination events by at least one to two orders of magnitude [29-32]. p53 has also been shown to interact with proteins involved in homologous DNA recombination processes, namely the initial strand transferase Rad51 and the Rad51 complex partners BRCA1 and $2[24,33]$. With respect to the breast cancer susceptibility gene products BRCA1 and BRCA2, functions in DNA repair, in the assembly of ionizing radiation-induced Rad51 complexes, in cell cycle control via transcriptional regulation of $p 21^{\text {WAFI/CIPI }}$ and in mediating apoptosis via GADD45 have been ascribed [34-37]. Concerning the mechanism underlying the control of homologous recombination events by $\mathrm{p} 53$, we suggested that p53 monitors the fidelity of strand exchange events [32]. SV40-virus based recombination assays in combination with in vitro binding studies unveiled qualitative and quantitative correlations between the binding affinities for heteroduplex joints with certain mismatches and the inhibition of DNA exchange events creating the corresponding DNA intermediates. Since homologous recombination processes are frequently associated with DNA synthesis, it is interesting to note that $\mathrm{p} 53$ was found to excise mispaired nucleotides from DNA in a polymerase $\alpha$ based in vitro replication assay [38]. Before $\mathrm{p} 53$, another tumor suppressor, $\mathrm{MSH}$ 2, had already been described to counteract DNA exchange processes between divergent sequences beyond its central role in postreplicative mismatch repair [39]. In agreement with the idea that p53 and $\mathrm{MSH} 2$ perform complementary functions in controlling the fidelity of homologous recombination processes, mice nullizygous for both MSH2 and p53 display synergistically increased cancer susceptibilities [40].

The critical question, whether the control of spontaneous and radiation-induced homologous recombination processes is tied to p53's growth regulatory functions was answered unequivocally by three groups [41-43]: Analyses of cell lines, expressing either different p53 mutants or wildtype p53 together with the p53-antagonist HDM2, demonstrated that recombination control is performed independently of p53-functions in transcription and cell-cycle control. Furthermore, it was observed that small protein amounts are sufficient for the inhibition of recombination processes by $\mathrm{p} 53$, whereas growth-related functions are exerted in a dose-dependent manner. These findings support the dual role model (see Figure 1), which attributes distinct functions to p53 in its latent and in its activated state, respectively [24]. It is important to note that homologous recombination in mitotically growing cells is suppressed by a factor of 1000 as compared to meiotic recombination. This might explain why meiotic exchange rates are not further elevated by the loss of p53 functions [44]. On the other hand, elevated frequencies of Rad51-dependent recombination was observed to accompany cellular immortalization processes [45]. Con- 
sidering the experimental data, which describe the regulatory role of wild-type p53 in DNA exchange processes of mitotically growing cells [41-43], the surveillance of homologous recombination by p53 is a good candidate to play a role in restraining spontaneous DNA rearrangements. Consequently, p53 might prevent tumor formation both by functions in growth regulatory and in repair processes.

\section{REFERENCES}

[1] McGill G, Fisher DE. p53 and cancer therapy: a doubleedged sword. J Clin Invest. 1999;104:223-225.

[2] Sherr CJ. Tumor surveillance via the ARF-p53 pathway. Genes Dev. 1998;12:2984-2991.

[3] Lane DP. Cancer: p53, guardian of the genome. Nature. 1992;358:15-16.

[4] Levine A. p53, the cellular gatekeeper for growth and division. Cell. 1997;88:323-331.

[5] Nelson WG, Kastan MB. DNA strand breaks: the DNA template alterations that trigger p53-dependent DNA damage response pathways. Mol Cell Biol. 1994;14:18151823.

[6] Ljungman M, Zhang F, Chen F, Rainbow AJ, McKay BC. Inhibition of RNA polymerase II as a trigger for the p53 response. Oncogene. 1999;18:583-592.

[7] Lane D. Awakening angels. Nature. 1998;394:616-617.

[8] Sakaguchi K, Herrera JE, Saito S, et al. DNA damage activates p53 through a phosphorylation-acetylation cascade. Genes Dev. 1998;12:2831-2841.

[9] Wang X, Ohnishi K, Takahashi A, Ohnishi T. Poly(ADPribosyl)ation is required for p53-dependent signal transduction induced by radiation. Oncogene. 1998;17:2819-2825.

[10] Bunz F, Dutriaux A, Lengauer C, et al. Requirement for p53 and p21 to sustain G2 arrest after DNA damage. Science. 1998;282:1497-1501.

[11] Hermeking H, Lengauer C, Polyak K, et al. 14-3-3 sigma is a p53-regulated inhibitor of G2/M progression. $\mathrm{Mol}$ Cell. 1997;1:3-11.

[12] Smith ML, Chen I-T, Zhan Q, et al. Interaction of the p53-regulated protein Gadd45 with proliferating cell nuclear antigen. Science. 1994;266:1376-1380.

[13] Kazantsev A, Sancar A. Does the p53 up-regulated Gadd45 protein have a role in excision repair? Science. 1995;270:1003-1004.

[14] Kearsey JM, Shivji MKK, Hall PA, Wood RD. Does the p53 up-regulated Gadd 45 protein have a role in excision repair? Science. 1995;270:1004-1005.

[15] Carrier F, Georgel PT, Pourquier P, et al. Gadd45, a p53responsive stress protein, modifies DNA accessibility on damaged chromatin. Mol Cell Biol. 1999;19:1673-1685.

[16] Kearsey JM, Coates PJ, Prescott AR, Hall PA. Gadd45 is a nuclear cell cycle regulated protein which interacts with p21 Cip1. Oncogene. 1995;11:1675-1683.

[17] Gottlieb E, Lindner S, Oren M. Relationship of sequence-specific transactivation and p53-regulated apoptosis in interleukin 3-dependent hematopoietic cells. Cell Growth Differ. 1996;7:301-310.

[18] Donehower LA, Harvey M, Slagle BL, et al. Mice deficient for p53 are developmentally normal but susceptible to spontaneous tumours. Nature. 1992;356:215-221.

[19] Deng C, Zhang P, Harper JW, Elledge SJ, Leder P. Mice lacking p21 WAF1/CIP1 undergo normal development, but are defective in G1 checkpoint control. Cell. 1995;82:675-684.

[20] Komarov PG, Komarova EA, Kondratov RV, et al. A chemical inhibitor of $\mathrm{p} 53$ that protects mice from the side effects of cancer therapy. Science. 1999;285:17331737.

[21] Oberosler P, Hloch P, Ramsperger U, Stahl H. p53catalyzed annealing of complementary single-stranded nucleic acids. EMBO J. 1993;12:2389-2396.

[22] Brain R, Jenkins JR. Human p53 directs DNA strand reassociation and is photolabeled by 8 -azido ATP. Oncogene. 1994;9:1775-1780.

[23] Mummenbrauer T, Janus F, Müller B, Wiesmüller L, Deppert W, Große F. p53 protein exhibits 3'-to-5' exonuclease activity. Cell. 1996;85:1089-1099.

[24] Janus F, Albrechtsen N, Dornreiter I, Wiesmüller L, Grosse F, Deppert W. The dual role model for p53 in maintaining genomic integrity. Cell Mol Life Sci. 1999;55:12-27.

[25] Blander G, Kipnis J, Leal JFM, Yu C-E, Schellenberg GD, Oren M. Physical and functional interaction between p53 and the Werner's syndrome protein. Biol Chem. 1999;274:29463-29469.

[26] Ford JM, Hanawalt PC. Li-Fraumeni syndrome fibroblasts homozygous for p53 mutations are deficient in global DNA repair but exhibit normal transcriptioncoupled repair and enhanced UV resistance. Proc Natl Acad Sci USA. 1995;92:8876-8880.

[27] Wang XW, Yeh H, Schaeffer L, et al. p53 modulation of TFIIH-associated nucleotide excision repair activity. Nat Genet. 1995;10:188-195.

[28] Ishizaki K, Ejima Y, Matsunaga T, et al. Increased UVinduced SCEs but normal repair of DNA damage in p53deficient mouse cells. Int J Cancer. 1994;58:254-257.

[29] Wiesmüller L, Cammenga J, Deppert WW. In vivo assay of p53 function in homologous recombination between simian virus 40 chromosomes. J Virol. 1996;70:737-744.

[30] Mekeel KL, Tang W, Kachnic LA, Luo C-M, DeFrank JS, Powell SN. Inactivation of p53 results in high rates of homologous recombination. Oncogene. 1997;14:18471857.

[31] Bertrand P, Rouillard D, Boulet A, Levalois C, Soussi T, Lopez BS. Increase of spontaneous intrachromosomal homologous recombination in mammalian cells expressing a mutant p53 protein. Oncogene. 1997;14:11171122.

[32] Dudenhöffer C, Rohaly G, Will K, Deppert W, Wiesmüller L. Specific mismatch recognition in heteroduplex intermediates by p53 suggests a role in fidelity control of homologous recombination. Mol Cell Biol. 1998;18:5332-5342.

[33] Marmorstein LY, Ouchi T, Aaronson SA. The BRCA2 
gene product functionally interacts with $\mathrm{p} 53$ and RAD51. Proc Natl Acad Sci USA. 1998;95:13869-13874.

[34] Somasundaram K, Zhang H, Zeng YX, et al. Arrest of the cell cycle by the tumour-suppressor BRCA1 requires the CDK-inhibitor p21 WAF1/CIP1. Nature. 1997;11:187-190.

[35] Patel KJ, Yu VPCC, Lee H, et al. Involvement of Brca2 in DNA repair. Mol Cell. 1998;1:347-357.

[36] Gowen LC, Avrutskaya AV, Latour AM, Koller $\mathrm{BH}$, Leadon SA. BRCA1 required for transcriptioncoupled repair of oxidative DNA damage. Science. 1998;281:1009-1012.

[37] Yuan SS, Lee SY, Chen G, Song M, Tomlinson GE, Lee EY. BRCA2 is required for ionizing radiationinduced assembly of Rad51 complex in vivo. Cancer Res. 1999;59:3547-3551.

[38] Huang P. Excision of mismatched nucleotides from DNA: a potential mechanism for enhancing DNA replication fidelity by the wild-type p53 protein. Oncogene. 1998;17:261-270.

[39] Modrich P, Lahue R. Mismatch repair in replication fidelity, genetic recombination, and cancer biology. Annu Rev Biochem. 1996;65:101-133.

[40] Cranston A, Bocker T, Reitmair A, et al. Female embryonic lethality in mice nullizygous for both Msh2 and p53. Nat Genet. 1997;17:114-118.
[41] Saintigny Y, Rouillard D, Chaput B, Soussi T, Lopez BS. Mutant p53 proteins stimulate spontaneous and radiation-induced intrachromosomal homologous recombination independently of the alteration of the transactivation activity and of the G1 checkpoint. Oncogene. 1999;18:3553-3563.

[42] Dudenhöffer C, Kurth M, Janus F, Deppert W, Wiesmüller L. Dissociation of the recombination control and the sequence-specific p53. Oncogene. 1999;18:57735784.

[43] Powell SN, Willers H, McCarthy E, Tang W, Wu B. Homologous recombination is suppressed by $\mathrm{p} 53$, independently from transactivation of p21 or activation of the G1/S cell cycle checkpoint, Program and Abstracts, Keystone Symposium on Molecular and Cellular Biology: "Molecular Mechanisms in DNA Replication and Recombination". Taos, New Mexico, USA. February 1622: 117. Abstract.

[44] Gersten KM, Kemp CJ. Normal meiotic recombination in p53-deficient mice. Nat Genet. 1997;17:378-179.

[45] Xia SJ, Shammas MA, Shmookler Reis RJ. Elevated recombination in immortal human cells is mediated by HsRAD51 recombinase. Mol Cell Biol. 1997;17:71517158 .

${ }^{\dagger}$ E-mail: wi esmue1@hpi .uni-hamburg.de 

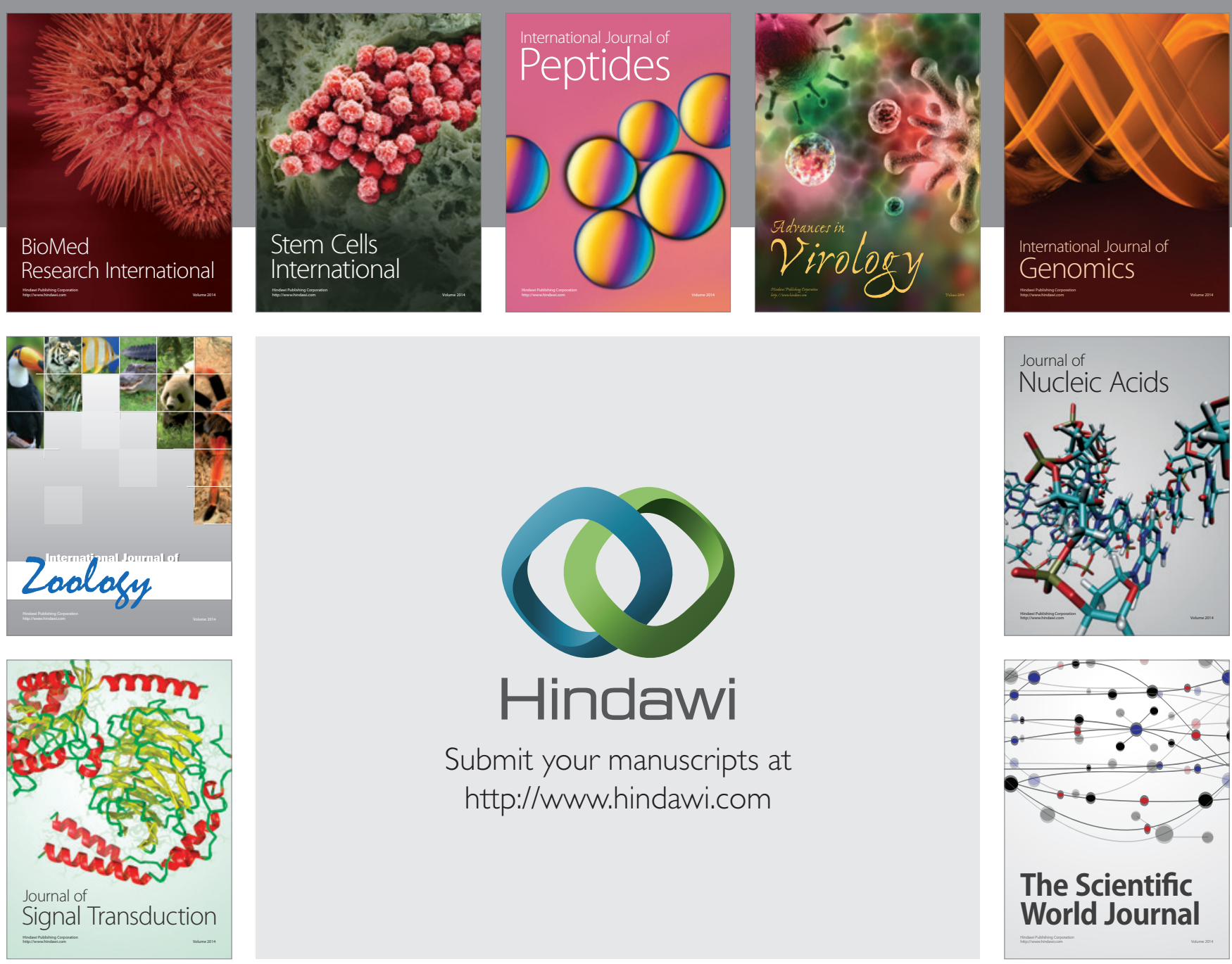

Submit your manuscripts at

http://www.hindawi.com
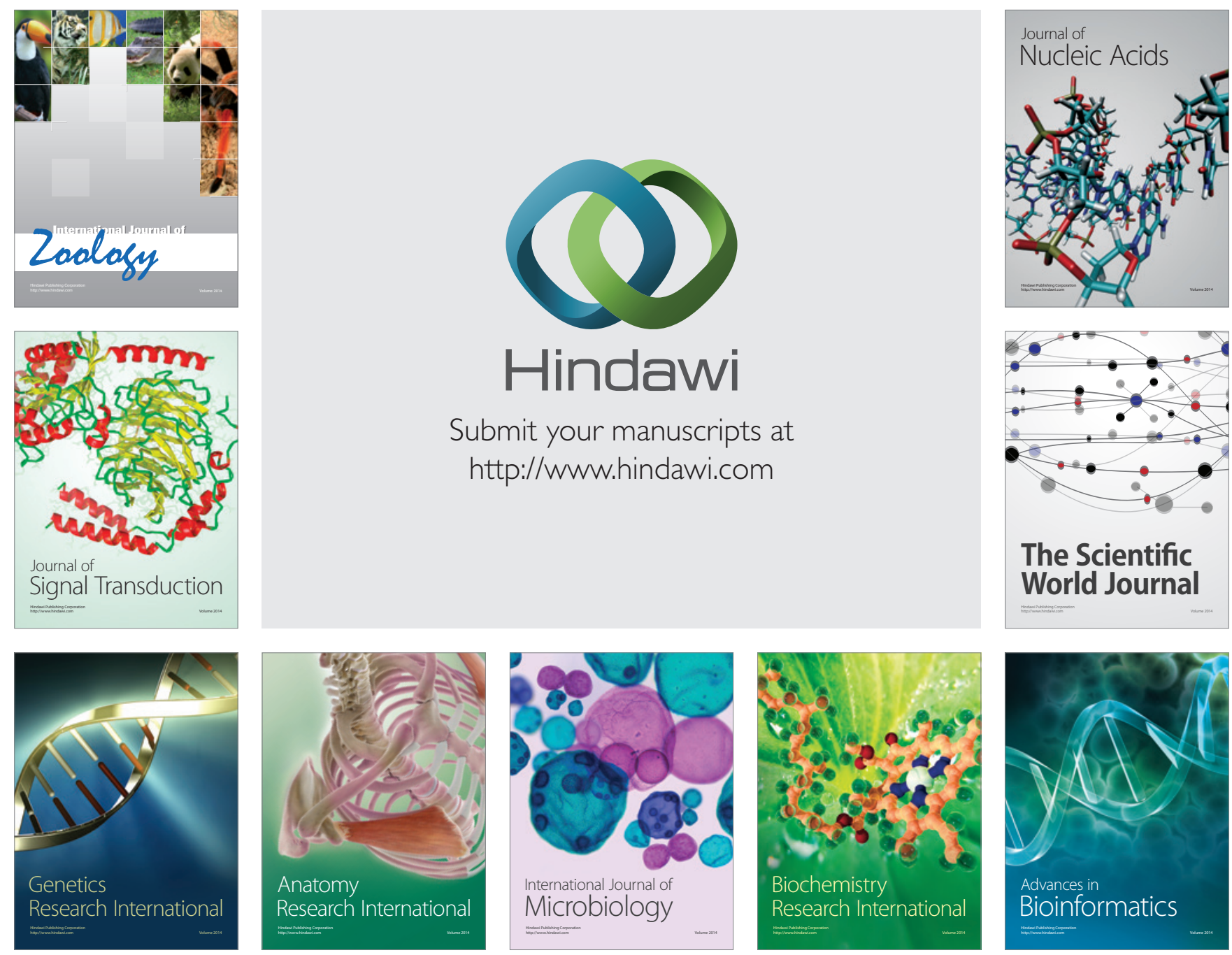

The Scientific World Journal
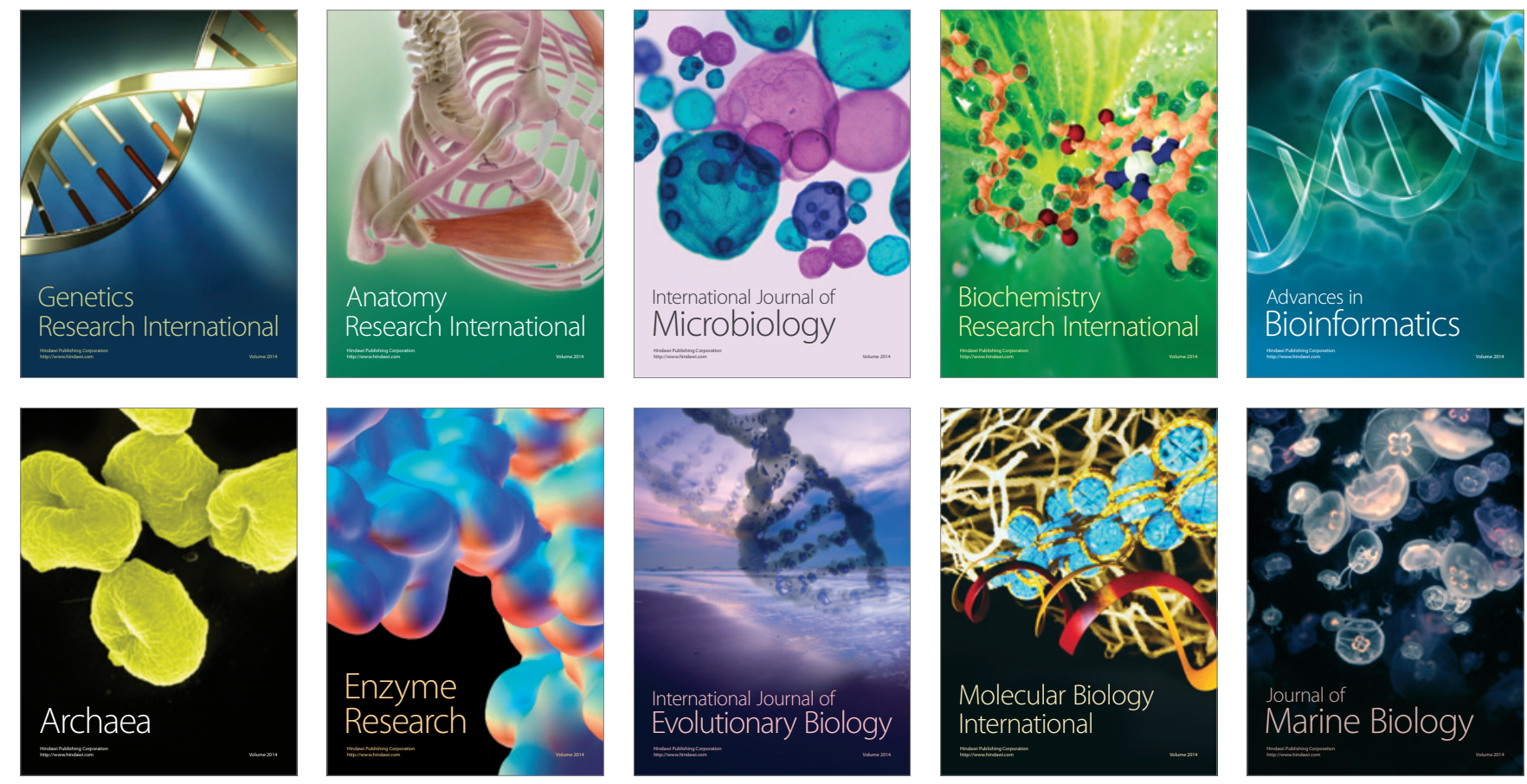